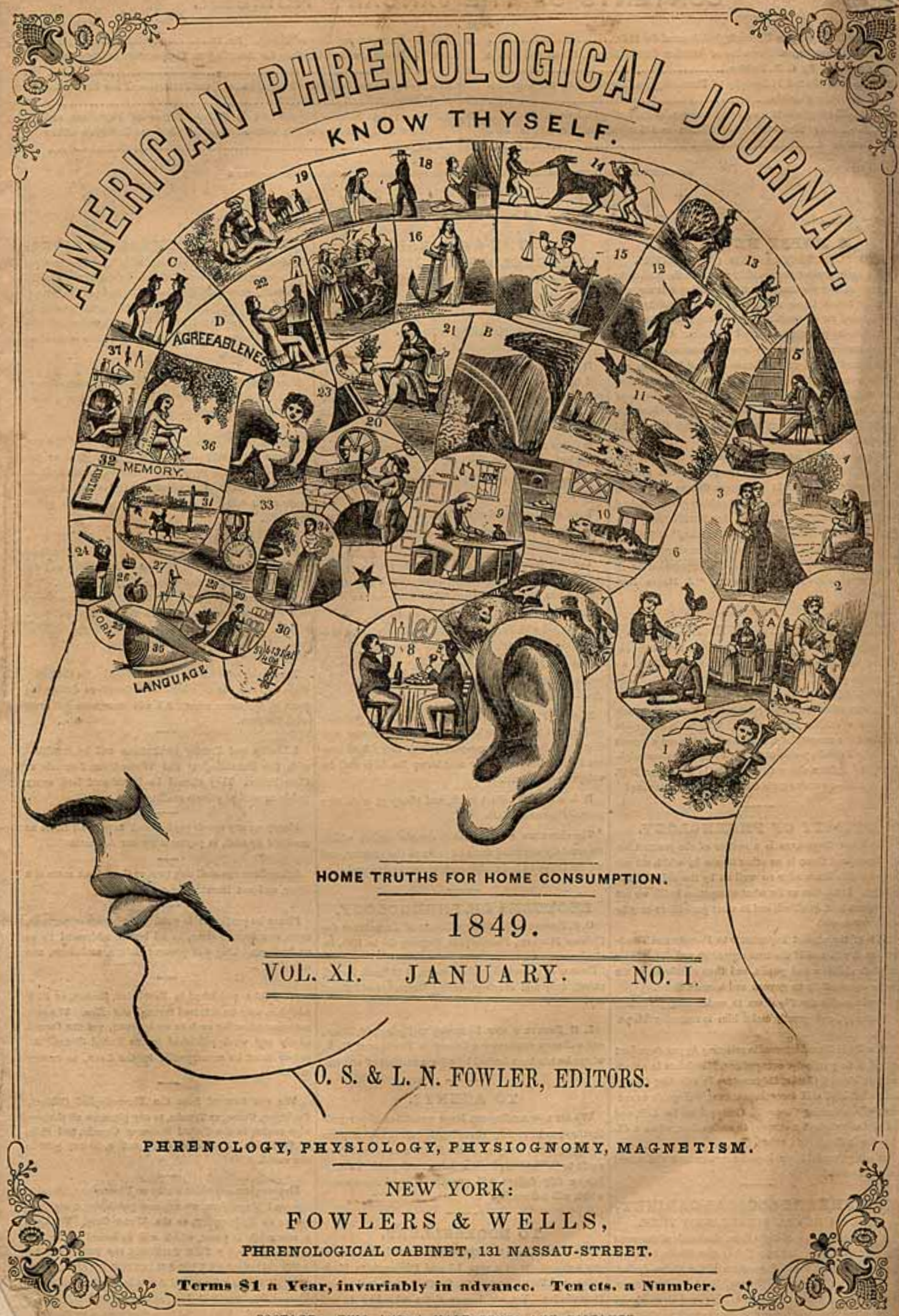
POSTAGE. TWO AND A HALF CENTS ANY DIETANCE. 


\title{
MENTS ALTERADES EN EL SEGLE XIX ELS RELATS D'EDGAR ALLAN POE I GUY DE MAUPASSANT
}

\author{
MARTín URdiales SHaW
}

En el present article s'aborda la confluència entre l'autor nord-americà Edgar Allan Poe (1809-1849) i l'autor francès Guy de Maupassant (1850-1893), que, a pesar d'estar adscrits a tendències literàries divergents (romanticisme enfront de realisme/naturalisme), van compartir interessos temàtics i formals inequívocs en l'àmbit del relat. Partint de les primerenques influències de la contística de Poe sobre l'escriptura de Maupassant, aquest treball se centra en una selecció dels relats de l'autor francès que el vinculen literàriament a Poe (tant en el terreny temàtic com en el narratològic), relacionats amb la fascinació d'ambdós autors per estats mentals atípics i narradors alterats o «alienats».

Paraules clau: Edgar Allan Poe, Guy de Maupassant, relat, estats mentals, narradors, frenologia.

Edgar Allan Poe (1809-1849) i Guy de Maupassant (1850-1893) no van ser coetanis, encara que les seues trajectòries vitals, que se succeeixen en les dues meitats del segle XIX, semblen curiosament coincidents: ambdós van tenir vides curtes $\mathrm{i}$ intenses amb finals tràgics. Poe va morir dies després d'aparèixer delirant al carrer, i Maupassant va morir en un hospital psiquiàtric mesos després d'un intent de suïcidi. Van compartir visions escèptiques del medi social i cultural que els va tocar viure, davant del qual van desenvolupar una fascinació literària compartida per tot d'elements estranys i aliens als costums establerts. ${ }^{1}$

Encara que semble arriscat comparar un autor romàntic com Poe (que no va cultivar la novella) amb el realista/naturalista Maupassant (que no va escriure poesia) sí que resulta significatiu observar la confluència d'ambdós en l'àmbit del relat, que comprèn

\footnotetext{
En aquesta apreciació estic subratllant una determinada parcel·la dels interessos literaris de Maupassant. Molt més prolífic que Poe, l'univers temàtic dels seus relats és molt ampli, abastant temes diversos, com les condicions socials, la política, la cultura i la religió, les relacions sentimentals o la guerra francoprussiana de 1870 (veieu Urdiales Campos, 1993).
}

un nombre d'aspectes importants. L'obra de l'escriptor francès suma uns tres-cents relats (segons com es comptabilitzen les versions), i hi ha un clar consens entre la crítica de Maupassant sobre la superioritat estilística i qualitativa dels seus relats enfront de les seues sis novelles. Quant al nord-americà, exceptuant la novella curta Arthur Gordon Pym, Poe va cultivar únicament la poesia $\mathrm{i}$ el relat, gèneres que exalça $i$ busca relacionar estèticament en la seua coneguda ars poetica, The Philosophy of Composition, per ser els únics que el lector pot abordar sense interrupcions, «d'una tirada» ( $a$ single sitting) (Poe, 1967).

Abans d'abordar les claus literàries que vinculen Maupassant amb Poe en aquest gènere, convé recordar com s'introdueix l'obra de l'escriptor nord-americà a França. És Charles Baudelaire, el «poeta maleït» qui tradueix al francès els relats més significatius d'Edgar Allan Poe, en una primera edició de 1856, Histoires extraordinaires, que reuneix tretze relats, i que és complementada el 1857 amb Nouvelles histoires extraordinaires, que n'inclou vint-i-tres més (1998). Com que Maupassant no parlava anglès, és lògic pensar que la

En el segle xIX es va popularitzar la frenologia, avui considerada pseudociència, que es basava en la palpació externa del crani i assignava a cada regió del cervell una funció específica. Aquesta disciplina va tenir una àmplia influència literària. En l'obra de Poe podem trobar-la en diferents contes. A l'esquerra, portada de l'American Phrenological Journal (1849). 
seua lectura de Poe es va basar en aquestes primerenques edicions traduïdes de Baudelaire, que, conjuntament, van representar una part molt important de la creació de l'escriptor nord-americà, 36 d'un total de 73 relats.

L'interès de Maupassant per Poe es reflecteix ja en alguns articles de premsa, de tipus recensió o crònica literària, que l'autor francès va publicar a començament de la dècada de 1880, en dues revistes, Gil Blas i Le Gaulois, en les quals apareixerien també molts dels seus primers relats. ${ }^{2}$ En l'assaig titulat Les foules Maupassant compara Poe amb Hoffman en aquests termes: «aquells psicòlegs estranys, mig bojos, filòsofs singularment subtils, així com al·lucinats» (Le Gaulois, 23/3/82) i, un any més tard, en la seua contribució Le fantastique, torna sobre aquella comparació així: «el seu extraordinari poder aterridor ve d'aquella habilitat sàvia, d'aquella manera particular de fregar el terreny fantàstic i d'incomodar a través de fets naturals on, no obstant això, queda quelcom d'inexplicable i quasi impossible» (Le Gaulois, 7/10/83), una valoració certament interessant, en allò que té d'extensible a la creació literària del mateix Maupassant en alguns relats d'aquests anys, que culminaria en el seu cèlebre relat llarg de «possessió» Le horla $(1886 ; 1887)$.

\section{MAUPASSANT I POE: LES CONFLUĖNCIES NARRATIVES}

En aquesta mateixa etapa, i precisament en aquestes mateixes revistes, Maupassant publica dos relats en què hi ha referències explícites a narradors o personatges de Poe, i el que és més significatiu encara, és que els dits relats - de manera més o menys velada- semblen entrar en una relació intertextual amb arguments o personatges de Poe. Al començament de Le tic (Le Gaulois, 1884), Maupassant fa aquesta descripció introductòria de dos personatges:

Em van semblar [...] personatges d'Edgar Poe [...] L'home era alt i prim, una mica encorbat, amb els cabells completament blanc, massa canós per a una fisonomia encara jove; i la seua presència feia aquella fila austera que conserven els protestants. La filla [...] era baixeta, molt prima també, molt pàlllida, amb un aspecte fastiguejat, cansat,

2 Totes les citacions de relats o cròniques periodístiques de Maupassant que segueixen, han estat extretes (amb autorització) de les seccions «Cròniques» $\mathrm{i}$ «Contes» allotjades en l'exhaustiva web de José Manuel Ramos González (2013). aclaparat [...]. Era molt bella, aquesta xiqueta, d'una bellesa diàfana com d'aparició. [Traducció pròpia.]

Sense entrar en anàlisis contrastives detallades, cal dir que l'argument de Le tic recorda en gran mesura la part final del conegut relat de Poe, The Fall of the House of Usher, en el qual Madeleine Usher és soterrada «en vida» pel seu bessó al panteó familiar subterrani de la mansió, d'on aconsegueix escapar, coberta de sang, per a reclamar la vida / caiguda del seu germà (i amb ell, la de la casa) en una escena final de gran càrrega al·legòrica. En Le tic ocorre el mateix «soterrament en vida», i Maupassant sembla recrear superficialment alguns elements gòtics del relat de Poe: igual com els Usher, el pare i la filla, de classe benestant, viuen reclosos en un château i la jove reapareix coberta de sang després d'una terrible lluita per a escapar de la sepultura. Ambdós relats es basen en la catalèpsia, o quadres mèdics afins, però així com en «Usher» el soterrament de Madeleine pot llegir-se en clau simbòlica, ${ }^{4}$ en $L e$ tic sempre és clar que es tracta d'un terrible error propiciat per un estrany quadre mèdic, i el pare queda desolat davant de la (aparent) mort de la seua filla. Maupassant no pretén donar cap nivell simbòlic a Le tic i, encara que ambdós relats comparteixen narradors en primera persona, el de Poe és testimoni presencial dels fets, mentre que el de Maupassant escolta una història retrospectiva.

En un altre relat de Maupassant, Magnétisme (publicat originalment en la revista Gil Blas, 1882), un personatge racionalista al-ludeix als narradors de Poe, per burlar-se de les creences dels seus contertulians en experiències paranormals:

Comencem a parlar de telepatia, dels periples de Donato i dels experiments del Dr. Charcot. [...] Un de sol somreia, un jove enèrgic [...] la incredulitat del qual sobre tot això era tan absoluta que ni tan sols entrava en el debat [...] Repetia divertit: "Bestieses!, bestieses!, [...] M. Charcot,

\footnotetext{
«Ils me firent l'effet [...] de personnages d'Edgar Poe [...] L'homme était très grand et maigre, un peu voûté, avec des cheveux tout blancs, trop blancs pour sa physionomie jeune encore; et il avait dans son allure et dans sa personne... cette tenue austère que gardent les protestants. La fille [...] était petite, fort maigre aussi, fort pâle, avec un air las, fatigué, accablé [...] Elle était assez jolie, cette enfant, d'une beauté diaphane d'apparition.»

${ }^{4}$ A la llum del freqüent ús del doble en E. A. Poe, i la caracterització complementària dels bessons Roderick i Madeleine -ell, malalt d'una excessiva agudesa sensorial i ella, passiva, aparentment sorda i muda- alguns crítics llegeixen The Fall of the House Usher com un viatge a l'interior de la ment, en el qual s'entaula una batalla dialògica entre conscient i subconscient, $o$ bé raó enfront d'abús, en la qual Madeleine estaria associada a allò que Freud denominarà el «jo reprimit».
}

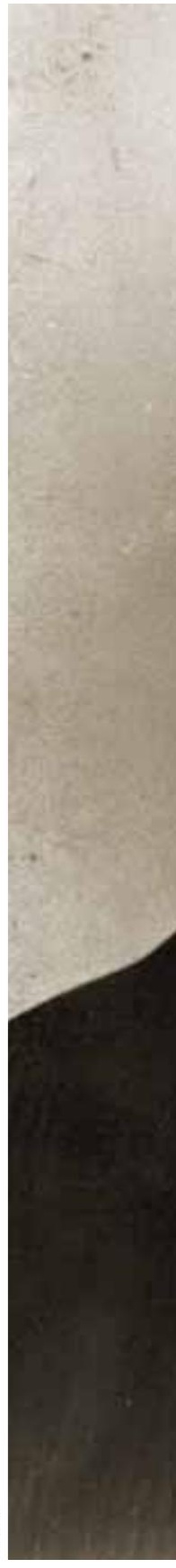




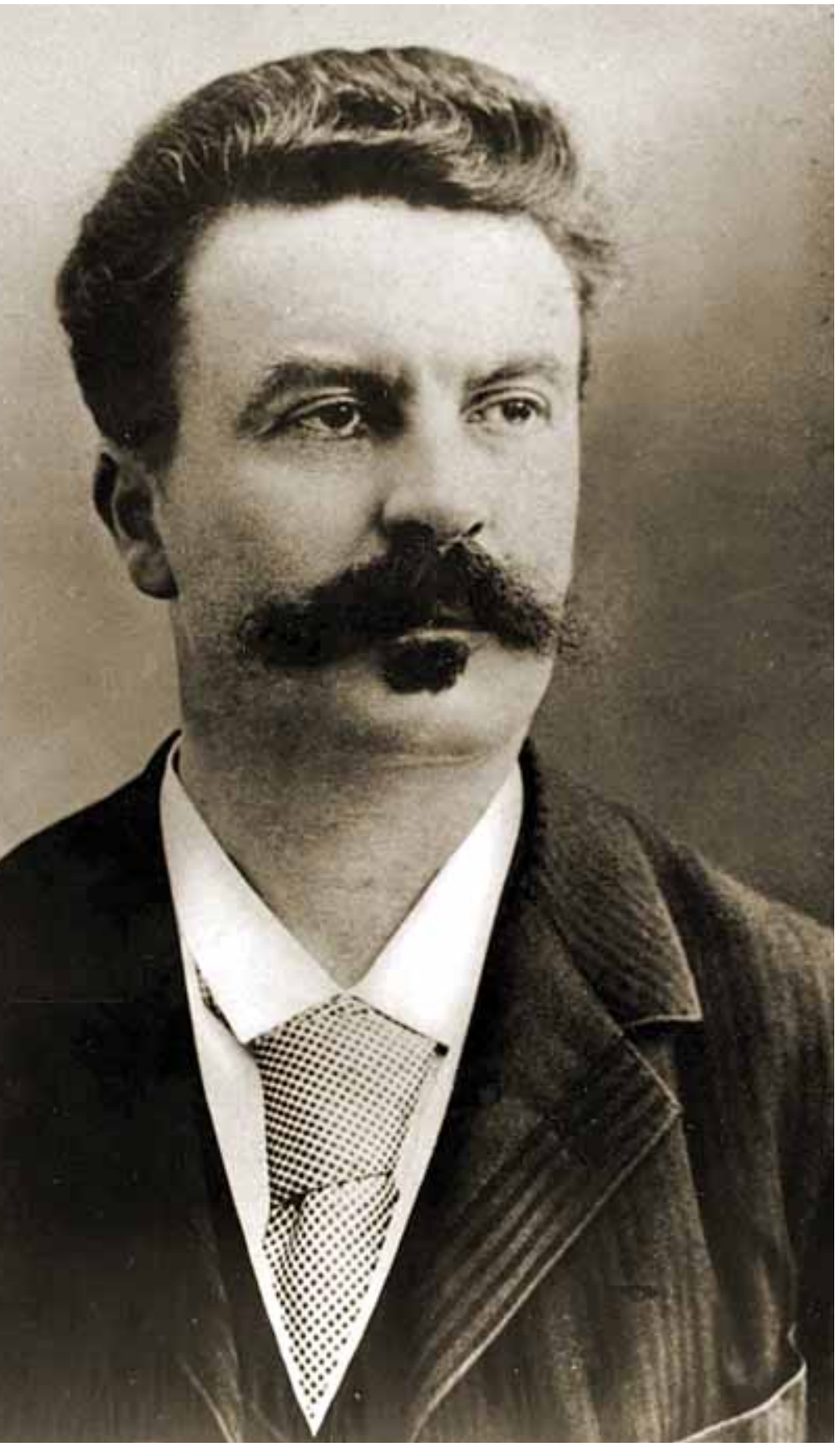

És interessant observar la confluència de l'escriptor Guy de Maupassant (en la imatge) amb Edgar Allan Poe en l'àmbit del relat. L'escriptor francès va publicar diversos relats en què hi ha referències explícites a narradors o personatges de Poe. Els relats d'ambdós escriptors contenen referències a la psique o a malalties com la catalèpsia.

«MAUPASSANT EXPLOTARÀ EL TEMA DE LA BOGERIA SOVINT EN LA DĖCADA DE 1880 I AQUESTA ACABARÀ AFECTANT-LO EN PERSONA» de qui diuen és un gran savi, em recorda aquells narradors del gènere d'Edgar Poe, que acaben guillats de tant de reflexionar sobre estranys casos de bogeria." [Traducció pròpia]. ${ }^{5}$

La referència a Jean-Martin Charcot (1825-1893) no deixa de ser significativa. Neuròleg i professor d'anatomopatologia, és considerat avui dia pare de la neurologia moderna per les seues descripcions de l'esclerosi, patologies de tipus neuromotor i atròfies musculars. Però l'al·lusió del personatge concerneix la fascinació de Charcot per la hipnosi, condició sobre la qual va experimentar en relació amb la histèria, i és en aquest àmbit en què el seu llegat resulta més controvertit des del punt de vista científic.

Maupassant hàbilment «emmarca» aquest relat amb aquests comentaris inicials del contertulià racionalista i descregut, per a tot seguit presentar la narració de dos successos que tan sols es poden explicar científicament mitjançant la telepatia: el contertulià escèptic mai reapareix, potser emmudit per l'exposició racionalista del que ha escoltat, i, per tant, la seua ironia sobre els narradors «bojos» de Poe - una possible referència al dement criminal de The Tell-Tale Heart-queda en dubte. D’altra banda, aquesta al·lusió és simptomàtica de la preocupació de Maupassant per la bogeria ja el 1882. És un tema que explotarà sovint en aquella dècada, i que acabaria afectant-lo en persona: el relat Qui sait? de 1890 (any i mig abans del seu intent de suïcidi) ja és interpretat per la crítica en clau autobiogràfica.

\section{DE LA FRENOLOGIA A LA PSIQUE: LA INFLUÈNCIA DE LES TEORIES DE L'ÈPOCA}

El relat Magnétisme té també un interès conjuntural, que transcendeix tant l'obra de Poe com la de Maupassant, però que ha de tenir-se en compte com a influència en aquests i en altres autors del segle XIX. A mitjan segle van proliferar i es popularitzaren teories que intentaven «estructurar» les funcions del cervell humà, i promovien una especial fascinació per les potencialitats d'aquest. La principal d'aquestes teories va ser la frenologia, que es basava en la palpació externa del crani, i que «compartimentalitzava» el cervell en nombroses regions, a les quals assignava funcions molt específiques. Avui considerada pseudociència, perquè clarament no tenia mètode científic adequat i es postulava com una visió

\footnotetext{
«On vint à parler du magnétisme, des tours de Donato et des expériences du docteur Charcot. [...] Un seul souriait, un vigoureux garçon [...] chez qui une incroyance à tout s'était ancrée si fortement qu'il n'admettait même point la discussion. [...] Il répétait en ricanant: "Des blagues! des blagues!" [...] M. Charcot, qu'on dit être un remarquable savant, il me fait l'effet de ces conteurs dans le genre d'Edgar Poë, qui finissent par devenir fous à force de réfléchir à d'étranges cas de folie.»
} 
determinista del comportament, en el seu plantejament «essencial» d'associar regions cerebrals amb funcions o capacitats, la frenologia és un antecedent de la neurologia moderna, que avui dia sí que pot identificar quines parts del cervell intervenen en les nostres capacitats. La frenologia va tenir el seu apogeu en la primera meitat del XIX i va exercir una àmplia influència literària. Es percep en la novel·la Moby-Dick de Herman Melville, en l'obra d'autors britànics, com Wilkie Collins (pare de la ficció criminal britànica) i Arthur Conan Doyle, que posa en boca del seu detectiu Sherlock Holmes deduccions basades en l'observació frenològica (Taylor, 1988). També és un referent en algunes caracteritzacions de personatges de les germanes Brönte i en la novel-la Dràcula de Bram Stoker. En algunes publicacions sobre frenologia, com l'American Phrenological Journal, s'escrivia també sobre «ciències afins», com la telepatia (magnetism, avui dia telepathy) o la fisonomia, que intentava relacionar trets físics amb personalitat (vegeu Wikipedia, principalment les seccions 2. Method, 5. Reception i 7. In Popular Culture). La influència de la frenologia en l'obra de Poe ha estat específicament estudiada per Erik Grayson (2005), qui rastreja la seua rellevància en els contes The Imp of the Perverse, The Fall of the House of Usher, The Black Cat i The Tell-Tale Heart.

En l'àmbit de la temàtica dels relats de Poe i Maupassant, crida l'atenció poderosament la simetria existent entre ambdós autors pel que fa a relats sobre la psique o el «jo», en un sentit ampli. Ací, es poden incloure tots aquells relacionats amb la demència, relats confessionals de criminals alterats, relats que impliquen un doppelganger (doble del jo), i relats sobre estats onírics o d'al·lucinació, hipnosi, trànsits, catalèpsia i telepatia. La catalèpsia vincula Le tic de Maupassant amb The Fall of the House of Usher, la part final de la qual, ja comentada, incorpora al seu torn el tema central de The Premature Burial, publicat anteriorment. Quatre relats d'ambdós autors tenen a veure amb formes de control o comunicació mental, com són la hipnosi, la telepatia, o la telecinesi: The Facts in the Case of M Valdemar i Mesmeric Revelation de Poe, i Un fou? i Magnétisme de l'autor francès. La conceptualització del doble o doppelganger ha estat sovint comentada per la crítica de Poe com un patró comú a diversos relats: s'ha relacionat amb (almenys) The Fall of the House of Usher, William Wilson, The Tell-Tale Heart i The Man of the Crowd, tres dels quals culminen amb la mort violenta del doble, que pot implicar la mort del jo. Significativament, la presència d'un doble -sota denominacions com «invisible», «un altre», el de fora, que sembla posseir el jo, o habitar un món paral·lel a aquest- està en alguns dels relats més enigmàtics i famosos de Maupassant, relacionats amb la demència: Lettre d'un fou, Lui?, Le docteur H. G. i les dues versions de Le horla. Caldria afegir

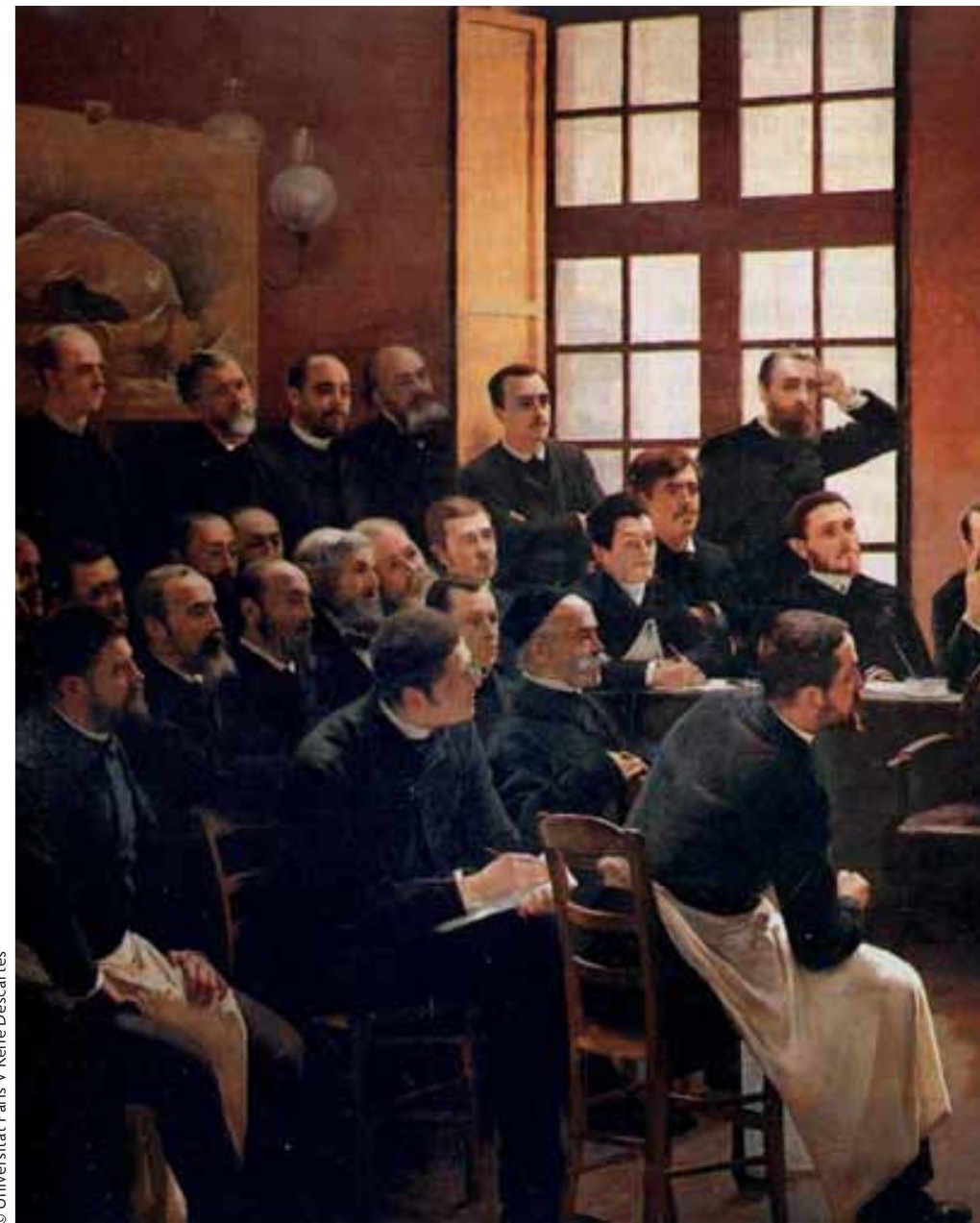

André Brouillet, 1887. Una lliçó clínica en la Salpêtrière. Oli sobre taula, $425 \times 300 \mathrm{~cm}$. En els escrits de Guy de Maupassant es troben referències a la ciència del moment, com és el cas del metge Jean-Martin Charcot, considerat com un dels pares de la neurologia moderna. En el relat Magnétisme, Maupassant hi fa al-lusió pels seus experiments amb la hipnosi en relació amb la histèria. En el quadre, observem el metge francès en una demostració davant els seus alumnes.

ací, subsidiàriament, alguns relats onírics o al·lucinatoris que, sense tractar sobre dobles, s'ocupen d'estats mentals aliens a la consciència normal: La nuit, L'endormeuse, Sur l'eau, L'homme de Mars i Rêves.

A part d'aquests paral-lelismes temàtics, convé fixar-se també en altres confluències, que entren en l'àmbit del to i la perspectiva narratius. Les influències del desenvolupament estructural de certs relats de Maupassant sobre autors nord-americans posteriors van ser descrites en un estudi formalista de Richard Fusco (1994), qui ja assenyala la rellevància de Poe com a inspiració en la tècnica contística de l'autor francès. No obstant això, Fusco amb prou feines toca un aspecte molt cridaner d'aquesta influència, que és el particular ús que fan Poe i Maupassant de la primera persona. La primera persona narrativa és freqüent en Poe, però així com alguns d'aquests narradors pretenen racionalitzar, «mitjançar» davant del lector la narració de fets insòlits (The Fall 


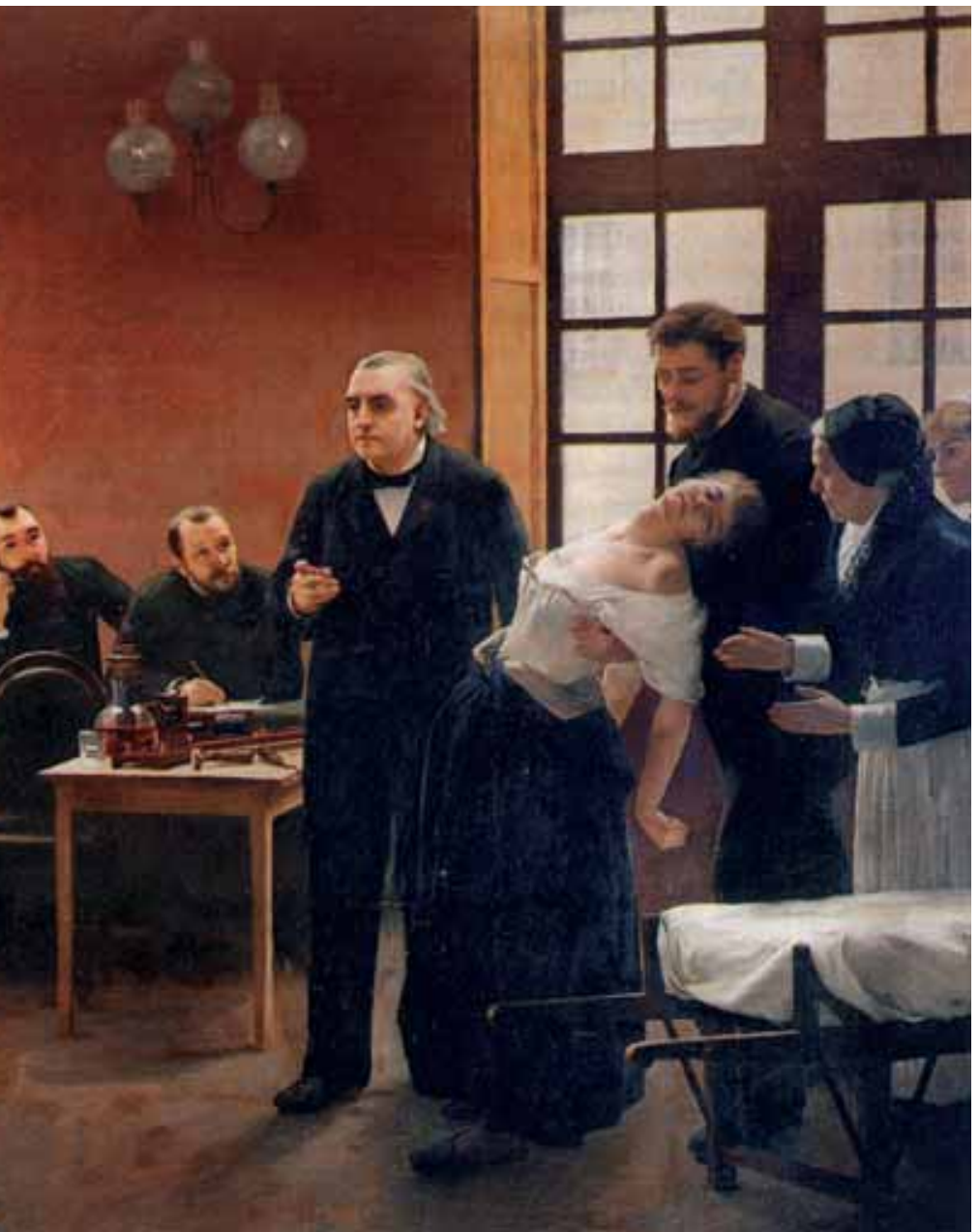

of the House of Usher n'és un exemple representatiu), altres vegades Poe enfronta directament el lector amb narradors alterats, o que es van agitant progressivament, en certs relats on l'insòlit no està només (o tant) en la naturalesa dels fets sinó també en la relació que hi manté el narrador -com a perpetrador-: així funcionen essencialment William Wilson, The Tell-Tale Heart, The Black Cat i The Imp of the Perverse, tots relats confessionals. El crític Christopher Benfey ha descrit amb precisió les intencions del narrador-criminal en aquests $\mathrm{i}$ altres relats afins:

The Tell-Tale Heart, The Black Cat i The Imp arrepleguen una confessió: una confessió perversa, ja que sense, els assassinats passarien inadvertits [...]. El temor dels criminals no és ser descoberts, sinó ser incompresos. [Traducció pròpia]. ${ }^{6}$

És significatiu observar fins a quin punt aquesta valoració de Benfey sobre la por a la incomprensió és extrapolable a alguns narradors en primera persona de

${ }^{6}$ «The Tell-Tale Heart, The Black Cat and The Imp all record a confession -a perverse confession since the crimes would otherwise have been undetected. [...] The fear of the criminals is not... being caught, it is the fear of being misunderstood.» (Benfey, 1993:37).
Maupassant. Els relats Lui? (1883), Le Horla (versió 1887, diari), i Qui Sait? (1890) adopten la perspectiva de narradors molt alterats, que dubten del seu trellat, generalment davant de la consciència o percepció de «dobles» o fets impossibles. El lector es troba ací en la difícil situació d'arreplegar el testimoni de narradors que intenten fer-lo partícip d'una experiència incomprensible, més enllà de l'àmbit racional. En altres casos, el paral·lelisme va encara més enllà, com ocorre amb el relat Fou? (1882) en què l'agitat narrador, criminal i dement, s'assembla extremadament al de Poe en The Tell-Tale Heart (Urdiales Shaw, 2012): ambdós exposen amb detall la seua percepció de la víctima, els preparatius del crim, i fins i tot la seua justificació material per a cometre'l, en un intent desesperat d'obtenir l'aprovació i la complicitat dels lectors. ()

\section{REFERÈNCIES}

Baudelaire, C., 1998. Edgar Allan Poe (Trad. C. Santos). Visor. Madrid. Benfey, C., 1993. "Poe and the Unreadable: "The Black Cat" and "The TellTale Heart”». En Silverman, K. (ed.). New Essays on Poe's Major Tales. Cambridge University Press. Cambridge.

FusCo, R., 1994. Maupassant and the American Short Story: Influence of Form at the Turn of the Century. Penn. State University Press. Philadelphia. Grayson, E., 2005. «Weird Science, Weirder Unity: Phrenology and Physiognomy in Edgar Allan Poe». Mode 1: 56-77.

PoE, E. A., 1967. Selected Writings. Penguin Books. Harmondsworth.

Poe, E. A., 1984. Complete Stories \& Poems. Doubleday. Londres.

Ramos GonzÁlez, J. M., 2013. «Guy de Maupassant». IES A Xunqueira. Pontevedra. Disponible en: <http://www.iesxunqueira1.com/maupassant/>. TAYLOR, J. B., 1988. In the Secret Theatre of Home: Wilkie Collins, Sensation Narrative and 19th Century Psychology. Routledge. Londres.

Urdiales Campos, M., 1993. La Francia Decimonónica a través de los Cuentos de Guy de Maupassant. PPU Ediciones. Barcelona.

Urdiales Shaw, M., 2012. «De/mentes criminales: Edgar Allan Poe y Guy de Maupassant». InterseXiones, 3: 67-79.

WikipediA. «Phrenology. 2. Method; 5. Reception; 7. In Popular Culture.» En Wikipedia. Disponible en: <http://en.wikipedia.org/wiki/Phrenology>

\section{ABSTRACT}

\section{Disturbed Minds in the Nineteenth Century: the Tales of Edgar Allan Poe and Guy de Maupassant.}

This article addresses a meeting of the minds between the American author Edgar Allan Poe (1809-1849) and the French author Guy de Maupassant (1850-1893). Although these authors belonged to opposing literary trends (romanticism versus realism/naturalism), their storytelling shared unmistakable thematic and formal interests. This paper begins by looking at the early influences that Poe's short stories had on Maupassant's writing, and then focuses on a selection of stories by the French author that link him to Poe in literary terms (both thematically and in narratological terms). These tales are related to the fascination both authors felt for atypical mental states and twisted or «disturbed» narrators.

Keywords: Edgar Allan Poe, Guy de Maupassant, story, mental disorder, storytellers, phrenology

Martín Urdiales Shaw. Professor titular del departament de Filologia Anglesa, Francesa i Alemanya. Universitat de Vigo. 